\title{
Relación entre didáctica, gerencia y el uso educativo de las TIC
}

Relationship between didactic, management and educational use of ICT

\author{
Volumen 17, Número 1 \\ Enero-Abril \\ pp. 1-31
}

Este número se publicó el $1^{\circ}$ de enero de 2017

DOI: http://dx.doi.org/10.15517/aie.v17i1.27198

\author{
María A. Cuberos de Quintero \\ Marisela Vivas García
}

Revista indizada en REDALYC, $\underline{\text { SCIELO }}$

Revista distribuida en las bases de datos:

LATINDEX, DOAJ, REDIB, IRESIE, CLASE, DIALNET, SHERPA/ROMEO, QUALIS-CAPES, MIAR

Revista registrada en los directorios:

ULRICH'S $, \underline{R E D I E}, \underline{\text { RINACE}}, \underline{\text { OEI }}, \underline{\text { MAESTROTECA }}, \underline{\text { PREAL, }}$ 


\title{
Relación entre didáctica, gerencia y el uso educativo de las TIC
}

\author{
Relationship between didactic, management and educational use of ICT
}

\author{
María A. Cuberos de Quintero ${ }^{1}$ \\ Marisela Vivas García ${ }^{2}$
}

Resumen: Este artículo científico presenta los resultados de una investigación cuyo objetivo fue determinar la relación existente entre didáctica, gerencia y el uso educativo de las tecnologías de la información y comunicación (TIC) en las instituciones de Educación Básica Secundaria del Municipio San José de Cúcuta-Norte de Santander, beneficiadas por el Programa Gubernamental Computadores para Educar en Colombia; esta fue realizada en el 2015. El enfoque metodológico utilizado fue mixto, la información se recogió mediante las técnicas encuesta escrita y entrevista oral; como instrumentos: el cuestionario estructurado y el guion de entrevista aplicado a 168 profesores y 14 gerentes educativos, respectivamente. Para el análisis de los datos se emplearon métodos estadísticos y de análisis de contenido, fundamentado filosóficamente en la transmodernidad. Los resultados evidencian una relación sinérgica incipiente entre la didáctica, gerencia y el uso educativo de las TIC derivada de la escasa formación, tanto del profesorado, como de los gerentes en competencias técnico-didácticas y de gestión, lo cual puede verse como una medición en pleno desarrollo del programa gubernamental Computadores para Educar, para la toma de decisiones pertinentes a los ajustes necesarios cónsonos con el propósito para el cual fue creado hacia la transformación institucional a favor de la calidad educativa.

Palabras clave: tecnología educativa, educación secundaria, didáctica, gerencia.

\begin{abstract}
This article Scientific presents the results of an investigation whose objective was to determine the relationship between didactic, management and educational use of Information Technology and Communication (ICT) in basic secondary education institutions in the municipality San José de Cucuta -Norte de Santander benefited by the Government Computers for Schools Program in Colombia, It was conducted 2015. The methodological approach was mixed, the information was collected by the techniques: survey and oral interview, as instruments structured questionnaire and interview guide applied to 168 teachers and 14 educational managers respectively, statistical data analysis and content analysis methods were used. It was based philosophically Transmodernity. The results show a synergistic relationship emerging between didactic, management and educational use of ICT resulting from poor training of both teachers and managers in didactic technical and managerial skills, delaying the institutional transformation in favor of educational quality.
\end{abstract}

Key words: educative technology, secondary education, didactic, management.

\footnotetext{
1 Investigadora de la Universidad Simón Bolívar, Cúcuta, Colombia. Doctor en Ciencias Gerenciales. Universidad Nacional Experimental Politécnica de la Fuerza Armada. Venezuela. Dirección electrónica: m.cuberos@unisimonbolivar.edu.co

2 Investigadora de la Universidad Simón Bolívar, Cúcuta, Colombia. Doctor en Innovaciones Educativas. Universidad Nacional Experimental Politécnica de la Fuerza Armada. Venezuela. Dirección electrónica: m.vivas@unisimonbolivar.edu.co
}

Artículo recibido: 28 de marzo, 2016

Enviado a corrección: 28 de junio, 2016

Aprobado: 21 de noviembre, 2016 


\section{Introducción}

Las tecnologías de información y comunicación (TIC) han conducido en la sociedad de la información y conocimiento a innovaciones; por ejemplo, en el campo educativo, al emplearse en los procesos de enseñanza y aprendizaje, así como en la administración de las instituciones escolares, aspecto visualizado por Joyanes $(1997)^{3}$ como transformaciones en el modo de coordinar a las personas y sus roles en la organización, la estructura y diseño de procesos, la cultura, las relaciones entre las entradas y salidas; por consiguiente, hoy, se vislumbra una estrecha relación entre la gerencia y la didáctica para el uso educativo de las TIC.

En Colombia, la presidencia de la República, el Ministerio de Tecnología de la Información y las Telecomunicaciones (Mintic), el Ministerio de Educación Nacional (MinEducación), el fondo TIC y el Servicio Nacional de Aprendizaje (SENA) han realizado un trabajo promotor de las TIC como un factor de desarrollo equitativo y sostenible al alcance de las comunidades educativas, haciendo énfasis en las sedes educativas públicas a través del Programa Computadores para Educar. Entre los resultados obtenidos en los años 20002014, , se tiene que más de siete millones de niños y jóvenes de un aproximado de 41 mil sedes educativas, entre ellas las más apartadas y rurales del país, experimentan una vida digital gracias a las posibilidades ofrecidas por la tecnología (Mintic y MinEducación, s.f.).

En el contexto de la ciudad de San José de Cúcuta, en el ámbito de las instituciones municipales de educación básica secundaria, se han incorporado las TIC a las prácticas pedagógicas del profesorado mediante el Programa Computadores para Educar. En este proceso, cobra valor el rol de la gerencia para el éxito en su implementación; por ello se ha buscado conocer cómo es la relación existente entre la didáctica y la gerencia en la implementación y uso educativo de las TIC en las instituciones beneficiadas por el programa.

Al buscar la investigación, la relación didáctica, gerencia y uso educativo de las TIC requirió, en primer lugar, fijar la concepción para los términos de la relación. Así, la didáctica se define como "la ciencia de la educación que estudia e interviene en el proceso de enseñanza y aprendizaje con el fin de conseguir la formación intelectual del educando" (Mallart, 2001, p. 5), en cuyo contenido se halla la normativa, la comunicación, el estudiantado, el profesorado y la metodología con la finalidad de que se logre la formación intelectual del estudiante, la optimización del aprendizaje, la integración de la cultura y el

\footnotetext{
3 Desde la transmodernidad como pensamiento filosófico que orientó a la investigación, se ha considerado al autor, pues, en el presente su pensamiento se revaloriza en la realidad de la globalización.
} 
desarrollo personal. La presencia de las TIC en el contexto educativo involucra revisar el rol de la didáctica para que se logre formar al estudiante mejorando la calidad de la educación en una nueva perspectiva cultural.

A la gerencia y administración de la organización le corresponde la conducción de la institución hacia el logro de sus objetivos al realizar una labor de guía partiendo de elementos provenientes del entorno y del seno organizacional a modo de información, que permitan la toma de decisiones adaptativas acordes con el cumplimiento de sus metas mediante actividades efectuadas por las personas que trabajan en ella, considerando la organización y división del trabajo (Van Den Berghe, 2005).

En el caso gerencial, las funciones de planificación, coordinación, dirección, ejecución y control se involucran con el cambio, las cuales han de adaptarse, siguiendo a Drucker (2002), a las condiciones del entorno en donde se hallan los profesores y profesoras, los recursos, medios informáticos y el estudiantado, cuya integración ha de orientarse a las metas y propósitos de la institución, que se corresponden con la mejora de la calidad educativa, pues según, Pineda (2009), las TIC son un medio por donde fluye el saber. De este modo, una relación que pudiese plantearse entre la gerencia y la didáctica en este entorno de cambio es el aprendizaje de manera efectiva, y alcanzar tal logro involucra una acción planificada del empleo de las TIC en el proceso de enseñanza y aprendizaje a fin de preparar para la sociedad del conocimiento.

Según International Society for Technology in Education (ISTE) (2007), la responsabilidad del ambiente adecuado en el aula y de preparar las estrategias de enseñanza y de aprendizaje para el aprovechamiento al máximo del uso de las tecnologías recae sobre el profesorado, quien ha de estar preparado, capacitado y actualizado; en caso contrario, listo para la adquisición de competencias, consideradas como el conjunto de saberes (conceptos, habilidades y actitudes...) que deben ser adquiridos, trabajados y aplicados para el desenvolvimiento eficaz en el proceso de formación y comunicación mediado por las TIC.

Al plantear el cambio con la implementación de las TIC en las instituciones educativas públicas, se requiere partir de la visión institucional que delinee quiénes tienen a su cargo la gerencia institucional, los que planifican, coordinan, organizan, dirigen y controlan ese proceso, vinculando la instalación de la plataforma tecnológica, la formación del profesorado para adquirir las competencias requeridas para el buen uso educativo de las TIC en las aulas y ejecutar de modo efectivo el proceso de enseñanza y aprendizaje. Consecuentemente, la 
gerencia educativa debe poseer conocimientos y competencias para gestionar el cambio, pues ha de adaptar la situación de la institución considerando los fines perseguidos, los lineamientos establecidos y el pensamiento estratégico que le permita abordarlo.

La relación entre la gerencia y la didáctica ante el uso educativo de las TIC debe involucrar el aprendizaje efectivo, la formación y presencia de competencias en el profesorado y la gerencia educativa, para que se efectúen los procesos de enseñanza y aprendizaje afines a las circunstancias que conducen al cambio. Ahora bien, lograr de modo integral tal relación implica un trazado estratégico y, por lo tanto, alcances de corto, mediano y largo plazo que para las instituciones de educación básica secundaria del municipio de San José de Cúcuta beneficiadas con el Programa Computadores para Educar se requieren descubrir. Así, para el abordaje de la investigación, se planteó como objetivo determinar la relación existente entre didáctica, gerencia y el uso educativo de las TIC en las instituciones de educación básica secundaria del Municipio San José de Cúcuta-Norte de Santander, beneficiadas por el Programa Gubernamental Computadores para Educar en Colombia.

El artículo se estructuró en 6 secciones: introducción, metodología, referente teórico: las TIC y su vinculación con la didáctica, las TIC y su vinculación con la gerencia educativa, resultados y análisis, conclusiones y referencias bibliográficas.

\section{Metodología}

El enfoque empleado para la recolección y análisis de la información fue mixto, en este, según (Hernández, Fernández y Baptista, 2006), lo cualitativo permite la dinámica entre los hechos y su interpretación en la búsqueda de comprender un fenómeno social complejo tal, y como lo observan los actores y actrices involucradas en el sistema. Los datos cuantitativos permiten establecer relaciones entre variables con la finalidad de obtener proposiciones precisas. Se buscó entender el fenómeno desde una visión holística considerando el todo, sin reducirlo al estudio de sus partes. Para la recolección de la información cualitativa, se utilizó una entrevista mediante un guion aplicado a catorce personas directoras o rectoras de las instituciones municipales de educación básica secundaria beneficiadas con el Programa Computadores para Educar del Municipio San José de Cúcuta, con el fin de recabar puntos de vista sobre las cuestiones organizativas gerenciales y didácticas que subyacen al uso educativo de las TIC. Se utilizó el análisis de contenido. Se destaca que desde lo ético se estableció un compromiso de confidencialidad en la recolección de la información, tomando en cuenta que, como los entrevistados trabajan en las instituciones beneficiadas con el 
programa ya mencionado, pudo existir interés en algunas de las respuestas para hacer entender que este ha sido implementado de manera efectiva, por lo que pudo existir cierto sesgo.

Para obtener la información cuantitativa, la técnica empleada fue la encuesta y como instrumento, el cuestionario estructurado, aplicado a 168 profesores y profesoras de las 14 instituciones objeto de estudio; el análisis de los datos se hizo mediante el empleo de métodos estadísticos. Ambas perspectivas se complementaron permitiendo el acercamiento al conocimiento real del fenómeno a sus problemas y cuestionamientos.

Filosóficamente se empleó el paradigma de la transmodernidad, al buscar la generación de conocimiento desde la "síntesis dialéctica de la tesis moderna y la antítesis postmoderna" (Rodríguez, 2004, p. 33), configurando una triada dialéctica: modernidad, posmodernidad, transmodernidad, para completar un proceso de tésis, antítesis y síntesis. De este modo, se consideraron entre los referentes algunos autores que revalorizan pensamientos del pasado.

\section{Referente teórico}

\subsection{Las TIC y su vinculación con la didáctica}

Actualmente, el conocimiento se ha transformado en el producto más valioso de todos y la educación en una nueva dimensión caracterizada por la presencia de desarrollos tecnológicos que han surgido desde la segunda mitad del siglo XX, facilitada en gran medida por la presencia de las TIC; por lo tanto, la educación y la formación son consideradas como los caminos más expeditos para producirlo y adquirirlo (Coll, Mauri y Onrubia, 2008). Frecuentemente se justifica la incorporación de las TIC a la educación formal aludiendo razones válidas como su potencial contribución al mejoramiento del aprendizaje y a la calidad de la enseñanza; los motivos de este hecho en algunas circunstancias son difíciles de asociar con las relaciones que intervienen entre su uso y el progreso que pudiera apreciarse en el aprendizaje en escenarios complejos, como los de educación, si se toma en cuenta la intervención paralela de otros factores que pueden influir en ese resultado y en ocasiones modificar las prácticas educativas (Coll, 2004).

En este orden de ideas, es necesaria la debida integración entre el diseño tecnológico y didáctico al incorporar las TIC al proceso de enseñanza y aprendizaje, aspecto importante para su uso eficiente, ya que ameritan ir acompañadas de una propuesta pedagógica explícita, global y precisa que contenga elementos como: planificación de temáticas, 
objetivos, actividades de enseñanza, aprendizaje y evaluación así como orientaciones y sugerencias sobre la manera de implementarlos en el desarrollo de dichas actividades (Onrubia, 2005).

Para que estos elementos se vean reflejados en actividades didácticas depende de las competencias que posean los profesores y las profesoras y de aprovechar las potencialidades que les ofrecen las TIC para representar, procesar, transmitir y compartir información, en aplicaciones de software informático y telemático, herramientas de navegación, de representación del conocimiento, de construcción de redes semánticas, hipermedia, diseño de estrategias didácticas, diversas formas de evaluación, bases de datos, elaboración de modelos de visualización, de comunicación sincrónica y asíncrona, de elaboración conjunta, entre otras. Su uso también dependerá de la presencia de las TIC en las instituciones en general y en las aulas en particular (Coll, Onrubia y Mauri, 2007).

Esta situación representa un reto para el personal docente, responsables educativos, gestores de las políticas públicas asociadas a innovación, tecnología, ciencia y educación, por cuanto "la mayoría de ellos son inmigrantes digitales" (Carneiro, 2002, p. 1); por tanto es necesario que adquieran competencias para la implementación de estrategias didácticas y planteamientos pedagógicos dirigidos al centro del proceso de formación tomando en cuenta que pertenecen a una generación que nació y crece inmersa en el uso de las tecnologías y como tal emprende el conocimiento desde fundamentos y razonamientos diferentes a las generaciones anteriores (Carneiro, 2002).

Para el empleo eficiente de las TIC en el ámbito educativo, los factores intervinientes en los procesos de enseñanza y aprendizaje deben ser modelados de acuerdo con la apropiación e integración que profesores y profesoras y estudiantes hagan de estas, en actividades que conduzcan al aprendizaje (Area, 2005; Cuban, 2001; Coll, Onrubia y Mauri, 2007; Hernández, 2005). Por ello es relevante tener en cuenta un cambio de paradigma para su uso (Coll y Marti, 2001), pues existe la tendencia a que profesores con una visión transmisora o tradicional del proceso de enseñanza y aprendizaje utilicen las TIC solo como apoyo o refuerzo en sus estrategias de presentación y transmisión de contenidos.

En este sentido, se espera que el profesorado con una visión constructivista las utilicen para promover y organizar actividades de búsqueda e investigación, aprendizaje por descubrimiento, trabajo autónomo, colaborativo y cooperativo. Según los autores citados, el uso que los docentes hacen de las tecnologías en la enseñanza es coherente con sus pensamientos pedagógicos y su visión de los procesos de enseñanza y aprendizaje, lo cual 
se considera un factor determinante en la implementación de las tecnologías en la educación.

Emplear las TIC en el aula con eficiencia es más complejo de lo que se esperaba, pues existe el riesgo de caer en el reduccionismo tecnológico y pedagógico si no se tienen las habilidades y destrezas necesarias para ello. Diversos resultados de investigación coinciden en que el uso de las TIC no hace posible ni de forma automática la transformación, innovación y mejora de las prácticas educativas (Cabero, 2007). La relación entre las TIC, la pedagogía y la didáctica se ve permeada por la visión y actitud que tengan los profesores en cuanto a su uso educativo. La clave para entender y valorar el impacto de las TIC en el proceso de enseñanza y aprendizaje está en las actividades que realicen profesores y estudiantes en función de las posibilidades de comunicación, intercambio, acceso y procesamiento de la información que les subyacen (Area, 2005, Cabero, 2007, Coll, 2004).

Por consiguiente, en el contexto de la investigación, se buscó conocer en el personal docente sobre el manejo de herramientas en las TIC y su apropiación en la praxis pedagógica, considerando el ámbito tecnológico en el que se desenvuelven sus estudiantes y con los resultados establecer la relación existente entre didáctica, gerencia y uso educativo de las TIC en el contexto de las instituciones de educación básica secundaria del Municipio San José de Cúcuta, Norte de Santander-Colombia.

El establecimiento de la relación entre la didáctica y el uso educativo de las TIC puede originarse mediante una integración sinérgica que involucra la existencia de objetivos globales e interdisciplinares para comprender al ser humano de manera integral y así plantear una estrategia sistémica conducente a transformaciones de aspectos claves de la cultura escolar, entre ellos: el currículo, la pedagogía, la evaluación, la formación y o actualización de los profesores (Cabero, 2000; Comisión Económica para América Latina y el Caribe, Cepal, 2010).

\subsection{Las TIC y su vinculación con la gerencia educativa}

La gerencia educativa se define como el proceso mediante el cual se guía la función docente y administrativa de la institución escolar, así como las relaciones con el entorno para lograr los objetivos organizacionales en un trabajo integrado de sus diversos miembros con el propósito de ofrecer un servicio de calidad (Chiavenato, 2001; Van Den Berghe, 2005). El cumplimiento del proceso involucra la ejecución de las funciones de planificación, 
organización, coordinación, dirección y control establecidas para la gerencia, considerando la mejora de su gestión.

La presencia de las TIC en las instituciones educativas involucra un cambio, pues siguiendo a Aguilar, Pereyra y Miguel (s.f.), se entiende como un proceso que involucra el paso de un estado a otro, implicando alteraciones de carácter cuantitativo y cualitativo de la realidad; así que supone un proceso de transición que puede plantear posibilidades de mejora en la organización al buscar su supervivencia. Al implementarse el uso educativo de las TIC en las instituciones se inicia un cambio planeado o estratégico que comprende un modelo ideal de lo que debería ser, donde se traza la brecha existente entre lo real y lo ideal, convirtiéndose estas en el elemento motivador que implica que, al cerrarla, la organización tiende a su desarrollo y cambia de dirección (Sulbarán, 1998) ${ }^{4}$.

Al diseñar el modelo por seguir para integrar las TIC en el proceso educativo, se identifican las condiciones que deben ser rechazadas y reemplazadas, se proyectan etapas de desarrollo y se programa su implementación. El modelo solo podrá completarse cuando incorpore todas las fuerzas reconocibles relacionadas con cada subsistema de la organización: las directamente controlables y el ambiente externo donde se encuentra inmersa la institución bajo cuya influencia opera. Así, el diseño del cambio es premeditado y se establece una innovación ${ }^{5}$ estructural, un nuevo plan de acción o nuevas metas y, en consecuencia, un cambio en la filosofía de operación, clima o estilo de gestión (Sulbarán, 1998).

Por razón del cambio estratégico según Sulbarán (1998), el personal de gerencia en particular identifica brechas entre las condiciones deseadas en dimensiones tales como: efectividad, eficiencia, satisfacción del personal, etc., de allí que sus esfuerzos han de vincularse con la idea de encontrar mecanismos y métodos para lograr una organización más eficaz y eficiente, que prometa, a la vez, un clima o ambiente óptimo y satisfactorio para el trabajo productivo y creativo.

Ahora bien, esos esfuerzos han de involucrar áreas de diferente índole: (a) institucionales que según Tripier (2002) corresponden a valores, misión, visión; (b)

\footnotetext{
${ }^{4}$ Desde la transmodernidad como pensamiento filosófico que orientó a la investigación, se ha considerado al autor, pues, en el presente su pensamiento se revaloriza en la realidad de la globalización, plena de cambios.

5 Una Innovación "es la introducción de un producto (bien o servicio) o de un proceso, nuevo o significativamente mejorado, o la introducción de un método de comercialización o de organización nuevo aplicado a las prácticas de negocio, a la organización del trabajo o a las relaciones externas" (Organización para la Cooperación y el Desarrollo económicos (OCDE), 2005, p.49). Así, el cambio que se planea con nueva filosofía, modo de operar, nueva forma de gestionar para alcanzar metas nuevas o mejoradas constituye una innovación para la institución.
} 
estructurales, pues se plantean modificaciones en la división de los puestos de trabajo y renovaciones de roles; (c) tecnológicas al relacionar aspectos de la tecnología de la información y artefactos en general; (d) estratégicas al existir una vinculación con el reposicionamiento del mercado; y, (e) la cultural que resulta ser la más compleja, ya que los cambios solo se producen a través de los sujetos existentes en la organización, quienes han de posesionarse de la nueva visión, valores, rituales y maneras de hacer las cosas. Es este aspecto donde la gerencia educativa, siguiendo a la Comisión Económica para América Latina (Cepal) (2008), ha de ser el soporte en cuanto a compromiso y liderazgo.

Al entrar las TIC al ámbito educativo, se plantea la necesaria visibilización del estado deseable en el futuro para la institución escolar relacionando metas a corto plazo hasta el alcance de la visión institucional; de este modo, le corresponde al gerente educativo establecer cómo ha de ser reconocida su organización y cuáles son los valores corporativos que permitan responder en cuanto a institución: ¿quiénes somos?, ¿qué hacemos y para quienes?, ¿dónde nos ubicamos?, así como para determinar los logros que el ente espera para cumplir con su misión; por lo tanto, ser apto para responder: ¿a dónde queremos ir? ¿qué resultados queremos lograr?; en otras palabras, poseer la capacidad para plantear las metas y objetivos estratégicos (Armijo, 2009), incluyendo las estrategias y tácticas necesarias (IT Governance Institute, 2007) Asociación para la Auditoria y Control de Sistemas de Información (ISACA), 2007), definiendo metas y acciones para garantizar la supervivencia organizacional. Además, ha de contar con conocimiento acerca de los fines organizacionales y de su propio ser, de manera que pueda llegar al éxito, por lo que requiere poseer capacidades o competencias teleológicas (Habermas, 1929 cp; Cerdá, 2004).

En la planificación ha de estar involucrado el aprendizaje institucional, considerando estándares, pautas, normas existentes; por lo tanto, el gerente educativo ha de poseer aptitudes y capacidades para analizar las leyes y normativas así como las primacías gubernamentales, identificando la contribución de la organización a las prioridades del Plan Nacional de Desarrollo (Armijo, 2009), considerando la presencia y soporte de las TIC para mejorar la calidad educativa. Según López (2002), para lograr la implementación del cambio en una organización, ha de efectuarse un movimiento desde las creencias a las conductas, pasando por los valores, considerando las creencias, normas y actitudes de los miembros de la organización, en tal sentido las normas son para el autor, las reglas de conducta consensuada; por consiguiente, la presencia de las TIC en la institución escolar involucra la 
existencia en el gerente educativo de capacidades y competencias que le permitan guiar hacia un cambio cultural en la organización.

Asimismo, el gerente educativo ha de conocer acerca de los requerimientos necesarios del soporte técnico y de ambientación adecuada y contar con el apoyo de personal en el lugar para facilitar la integración de las TIC al currículo (Hofer, Chamberlin y Scot, 2004, cp; Aguaded y Tirado, 2008) y eliminar barreras que desde lo organizacional se han venido planteando con el ingreso de las TIC en la escuela, como lo son la disponibilidad de tiempo para crear material didáctico por parte del profesorado, el desarrollo profesional, la carencia de apoyo para la integración tecnológica, entre otros (Aguaded y Tirado, 2008) y así lograr la transformación de la cultura organizacional existente para instaurar el cambio planificado, perfilando un nuevo conjunto de creencias, experiencias y hábitos en los miembros de la institución, que caractericen su comportamiento ante los nuevos escenarios, atendiendo al concepto de cultura planteado por Azuaje (2005).

En el contexto educativo se delinea la presencia de recursos tecnológicos que se distribuyen, ponen en funcionamiento con un adecuado manejo, mantienen en buen estado y se vinculan con personas, personal docente y estudiantado que tienen como función de relación a los contenidos del currículo, junto a ellos, el personal administrativo acorde con las funciones de gestión en el ámbito digital y, en esa trama que se entreteje, se ha de cumplir la función gerencial de organización de manera que exista competitividad y soporte a las metas establecidas en la planificación (Arnoletto, 2014). Al organizar, diseñar y determinar funciones y tareas se crean unidades operativas, definen los circuitos y maneras de comunicación entre esas unidades, coordinan las labores con la construcción de relaciones permanentes entre entidades, se define el perfil del profesor idóneo al escenario tecnológico y se establece un grado de centralización o descentralización en la toma de decisiones (Van den Berghe, 2005).

Le corresponde a la gerencia educativa facilitar el funcionamiento y mejora de la operatividad con el empleo de las TIC en el proceso de enseñanza y aprendizaje mediante el entrenamiento y desarrollo operativo del personal para que pueda analizar y resolver los problemas que se presenten de manera mancomunada, promover la cooperación entre los participantes bajo la idea de que la institución es un ente único y que sus estrategias y tácticas deben ser analizadas y ejecutadas en forma integral, trabajar en un solo equipo promoviendo la armonía y el logro de mejores resultados (Van den Berghe, 2005). Así se involucra la función gerencial de coordinación en una adaptación mutua mediante la 
comunicación informal, supervisión directa y normalización de actividades con programación detallada (Arnoletto, 2014), facilitándose el cumplimiento de las funciones establecidas en la estructura organizacional bajo la propuesta de la integración de las necesidades futuras de la organización con selección y reclutamiento de personal, de manera que al existir crecimiento de esta, no hallan tropiezos en sus operaciones. Por consiguiente, desde la gerencia educativa ha de plantearse una vinculación estrecha entre coordinación y planificación de la estructura organizacional la cual depende, a su vez, de los planes y objetivos de la organización (Van den Berghe, 2005).

Ahora bien, el uso educativo de las TIC implica el alcance de metas a través de la ejecución de planes, dirección desde la supervisión, comunicación y motivación (Arnoletto, 2014), al gerente y administrador educativo, según Van den Berghe (2005), le corresponde liderar e influir en sus subordinados, promover la creación de un ambiente adecuado para una mayor productividad y desempeño de los profesores y empleados en la realización de sus actividades, bien sea que trabajen individualmente o en equipo, generar la sinergia entre la tecnología y el proceso educativo, favorecer la creatividad e innovación en el personal con sensibilidad social, orientar hacia el interés de la educación pública del país, siendo conscientes de las fuerzas externas para la organización que influyen en su funcionamiento.

En virtud de ello, el gerente de la institución educativa debe identificarse con lo estatal para que se concreten los cambios siendo el guía o líder; por lo que ha de poseer capacidades comunicacionales y de conceptualización, las cuales han de estar alimentadas en la experiencia y de los conocimientos adquiridos de las ciencias administrativas y del comportamiento. La gerencia educativa ha de seguir lineamientos establecidos para la ejecución del proyecto hacia el cambio, así lo ha iniciado desde una base de grados y asignaturas, debiendo instaurar secuencialmente una organización e infraestructura tecnológica apropiada, ejerciendo las funciones gerenciales acordes con la transformación pretendida.

Al procurar la realización de lo acordado en el plan para el contexto educativo con las TIC, se involucra la función gerencial de control, pues se requieren evaluaciones periódicas de los procesos para descubrir fallas que frenan el normal funcionamiento y efectuar correcciones, así se incluyen estándares o criterios de desempeño, correcciones a desviaciones en función de estos, exámenes de la calidad y suficiencia de los requerimientos de control (Van den Berghe, 2005). En el ámbito escolar, los procesos de enseñanza, el entrenamiento, la seguridad y aspectos de continuidad han de ser objeto de monitoreo; el 
gerente educativo en el escenario en donde se asienta la innovación debe buscar los efectos de las buenas prácticas, asesorarse con expertos y al implantarla, revisar los resultados para ajustar los procesos.

En razón de lo anterior, el gerente en el campo educativo para efectuar su rol ha de poseer competencias que permitan delinear el propósito organizacional, liderar la consecución de este en el contexto cambiante de la globalización, siguiendo las pautas y normas establecidas de manera que no exista riesgo de pérdida dentro de la institución que dirige ni en el entorno en donde se sitúa; así se plantea que el gerente debe poseer capacidades teleológicas, estratégicas y legales que le faciliten ser innovador de modo que pueda obtener los resultados de la organización y su sincronización, promoviendo la creación de equipos de trabajo auténticos que concebirán la diferencia en los resultados obtenidos por las organizaciones del futuro (Páez, s.f.).

Por consiguiente, en la relación existente entre la gerencia educativa y el uso de las TIC como recurso didáctico en el proceso de enseñanza subyace el ejercicio del conjunto de funciones gerenciales para el cambio desde competencias teleológicas, estratégicas y legales y así asentar una nueva cultura organizacional que involucre, en lo cotidiano, el empleo de las tecnologías en el proceso de enseñanza y aprendizaje para conducir hacia la visión institucional programada. Así, se buscó encontrar el estado de esta relación en el contexto de la investigación, por ello se procedió a indagar acerca de la ejecución y cumplimiento de las funciones gerenciales y la existencia de competencias teleológicas, estratégicas y legales.

\section{Resultados y análisis}

Lograr la visualización de la relación entre didáctica, gerencia y el uso educativo de las TIC en el contexto de las escuelas básicas secundarias del Municipio San José de Cúcuta, Departamento Norte de Santander Colombia, instituciones beneficiarias del Programa Gubernamental Computadores para Educar, involucró, por una parte, hallar información acerca del manejo de herramientas en las TIC y su apropiación en la praxis pedagógica, considerando el ámbito tecnológico en el que se desenvuelven sus estudiantes y, por otra, indagar acerca de la ejecución y cumplimiento de las funciones gerenciales y la existencia de competencias teleológicas, estratégicas y legales en los gerentes educativos en la implementación del programa mencionado, con el fin de encontrar, de manera integrada, la relación entre didáctica, gerencia y uso educativo de las TIC en el contexto de estudio. 
Al buscar conocer sobre el uso de herramientas en las TIC en la praxis pedagógica, la Tabla 1 muestra los siguientes resultados.

Tabla 1. Uso de herramientas en TIC en la praxis pedagógica

\begin{tabular}{|l|l|c|}
\hline \multicolumn{1}{|c|}{ Herramienta empleada } & Frecuencia de uso & Porcentaje \\
\hline Computador & Siempre & $41,1 \%$ \\
\hline Video beam & Algunas veces & $63,7 \%$ \\
\hline Internet disponibilidad de equipos en la & Siempre & $37,5 \%$ \\
\hline $\begin{array}{l}\text { No hay } \\
\text { institución }\end{array}$ & & $66,1 \%$ \\
\hline
\end{tabular}

Fuente: Elaboración propia de las investigadoras (2015).

Es el computador e internet dos de las herramientas que siempre se emplean, aunque llama la atención el 66,1 \% que indicó la no disponibilidad de equipos en la institución. En cuanto a la apropiación cuyos resultados se visualizan en la Tabla 2 , se desprende la existencia de una situación coherente entre el empleo del sistema operativo y los motores de búsqueda con el uso frecuente de internet ofrecido en la Tabla 1 en las instituciones en donde sí hay disponibilidad de recursos; se denota la utilización que se hace del correo electrónico y las bases de datos, pues el primero con un $80,7 \%$ es la herramienta que los profesores se han apropiado mejor y la usan con mayor facilidad, aunque el éxito de su aplicación didáctica depende de la intención y estrategia que emplee el docente. Con respecto a las bases de datos (MS Access, Apache Open Office Base...), son las aplicaciones en las cuales los profesores dicen tener nula apropiación en 19,6 \%, no son usadas en su labor administrativa ni de clase ante su desconocimiento.

Tabla 2. La apropiación de aplicaciones por parte del profesor

\begin{tabular}{|c|c|c|c|}
\hline Aplicación & Mucho & Poco & Nada \\
\hline Sistema operativo (Windows, Linux..) & $67,7 \%$ & $28,1 \%$ & $4,2 \%$ \\
\hline Programa de presentaciones (MS PowerPoint, Prezi...) & $45,8 \%$ & $46,4 \%$ & $7,8 \%$ \\
\hline Base de datos (MS Access, Apache OpenOffice Base...) & $19,6 \%$ & $53,4 \%$ & $27 \%$ \\
\hline Motores de búsqueda (Google, Yahoo, Bing, Terra...) & $67,7 \%$ & $27,5 \%$ & $4,8 \%$ \\
\hline Chat (MSN, Talk, Yahoo, Skype,... & $40,7 \%$ & $46,1 \%$ & $13,2 \%$ \\
\hline $\begin{array}{l}\text { Procesador de texto (MS Word, WordPad, Open office, Libre } \\
\text { office...) }\end{array}$ & $61,6 \%$ & $29,3 \%$ & $9,1 \%$ \\
\hline Hoja de cálculo (Excel, Apache Open Office Calc...) & $32,7 \%$ & $46,7 \%$ & $20,6 \%$ \\
\hline Navegador de internet (Internet Explorer, Firefox, Crome...) & $67,1 \%$ & $26,9 \%$ & $6 \%$ \\
\hline Correo electrónico (Hotmail, Gmail, Yahoo,...) & $80,7 \%$ & $16,9 \%$ & $2,4 \%$ \\
\hline $\begin{array}{l}\text { Redes sociales (Facebook, Twitter, Badoo, WhatsApp, } \\
\text { MySpace) }\end{array}$ & $53,9 \%$ & $35,9 \%$ & 10,2 \\
\hline
\end{tabular}

Fuente: Elaboración propia de las investigadoras (2015). 
Surge, de las tablas anteriores, un elemento técnico que es conveniente analizar, pues si existe un porcentaje de profesores que emplea siempre o algunas veces herramientas tecnológicas, se debe conocer sobre las competencias técnicas en el cuerpo profesoral con respecto a su utilización. En efecto, los encuestados respondieron, como se muestra en la Tabla 3, el uso dado a las herramientas.

Tabla 3. El uso de las herramientas

\begin{tabular}{|l|c|}
\hline \multicolumn{1}{|c|}{ Uso dado a las herramientas } & Porcentaje \\
\hline $\begin{array}{l}\text { De apoyo a los procesos de enseñanza y aprendizaje en la planificación y realización } \\
\text { de clases. }\end{array}$ & $69 \%$ \\
\hline $\begin{array}{l}\text { Formulación e implementación de estrategias de búsqueda, localización y selección } \\
\text { de recursos de información a través de sistemas en línea. }\end{array}$ & $52,4 \%$, \\
\hline De apoyo a procesos de gestión curricular. & $43,5 \%$ \\
\hline $\begin{array}{l}\text { Para interactuar con sus estudiantes y colegas, siguiendo protocolos propios de } \\
\text { integración curricular de las TIC en el proceso de enseñanza y aprendizaje. }\end{array}$ & $35,7 \%$ \\
\hline
\end{tabular}

Fuente: Elaboración propia de las investigadoras (2015).

Como se puede observar, el $69 \%$ expresa que las herramientas son apoyo a los procesos de enseñanza y aprendizaje en la planificación y realización de clases, y solo el $35,7 \%$ manifiesta que se emplean para interactuar con sus estudiantes y colegas, siguiendo protocolos propios de integración curricular de las TIC en el proceso de enseñanza y aprendizaje.

Además, al preguntar a los 168 docentes encuestados sobre cuáles son las competencias que desde el punto de vista técnico poseen y aplican en el proceso de enseñanza y aprendizaje mediante el uso de las TIC, se obtuvo como resultado lo que se muestra en la Tabla 4.

Tabla 4. Las competencias que desde el punto de vista técnico posee el profesor y aplica en el proceso de enseñanza y aprendizaje mediante el uso de las TIC

\begin{tabular}{|l|l|}
\hline \multicolumn{1}{|c|}{ Competencias técnicas } & \multicolumn{1}{|c|}{ Porcentaje } \\
\hline $\begin{array}{l}\text { Formula e implementa estrategias de búsqueda, localización y selección de } \\
\text { recursos de información a través de sistemas en línea. }\end{array}$ & $52,4 \%$ \\
\hline $\begin{array}{l}\text { Usa recursos digitales de apoyo a los procesos de enseñanza y aprendizaje } \\
\text { en la planificación y realización de clases. }\end{array}$ & $69 \%$ \\
\hline $\begin{array}{l}\text { Usa sistemas digitales de comunicación para interactuar con sus estudiantes } \\
\text { y colegas, siguiendo protocolos propios de Integración curricular de las TIC } \\
\text { en el proceso de enseñanza y aprendizaje }\end{array}$ & $35,7 \%$ \\
\hline $\begin{array}{l}\text { Usa recursos digitales de apoyo a procesos de gestión curricular en la la } \\
\text { planificación y realización de las clases. }\end{array}$ & $43,4 \%$ \\
\hline
\end{tabular}

Fuente: Elaboración propia de las investigadoras (2015). 
De los resultados se desprende que aún existen profesores que no poseen competencias técnicas para abordar el proceso de enseñanza y aprendizaje con las TIC. Aunque se plantea que junto a estas debe existir conocimiento con respecto a los nuevos paradigmas como elemento productor de ideas innovadoras con capacidad para transformar la educación, una vez los profesores deduzcan qué y por qué vale la pena cambiar de modelo y de paradigma, lo que implica que desde la gerencia se promueva el cambio de la visión institucional por la presencia de las TIC en el proceso de enseñanza y la implementación de las tecnologías en el aula de clase, involucrando el aprendizaje organizacional planteando al profesorado el reto del mismo.

En razón de ello, se investigó acerca de las acciones que la gerencia de la institución efectuó en la planificación institucional para la implementación del uso educativo de las TIC, obteniendo como resultado el contenido de la Tabla 5.

Tabla 5. Acciones que la gerencia de la institución efectuó en la planificación institucional para la implementación del uso educativo de las TIC

\begin{tabular}{|l|l|}
\hline \multicolumn{1}{|c|}{ Acciones efectuadas } & Porcentaje \\
\hline $\begin{array}{l}\text { Planificó el cambio de la visión institucional por la presencia de las TIC en el proceso } \\
\text { de enseñanza y aprendizaje. }\end{array}$ & $61,9 \%$ \\
\hline $\begin{array}{l}\text { Planificó el aprendizaje institucional ante la implementación de las TIC en el proceso } \\
\text { de enseñanza y aprendizaje. }\end{array}$ & $36,9 \%$ \\
\hline $\begin{array}{l}\text { Comunicó el cambio de la visión institucional por la presencia de las TIC en el proceso } \\
\text { de enseñanza y aprendizaje. }\end{array}$ & $27,4 \%$ \\
\hline $\begin{array}{l}\text { Planificó la implementación de las TIC en el proceso de enseñanza y aprendizaje, } \\
\text { considerando ciertos grados y asignaturas como base inicial para la ejecución del } \\
\text { proyecto en concordancia con lineamientos establecidos }\end{array}$ & $44 \%$ \\
\hline Estableció un cronograma de actividades para la implementación de las TIC. & $36,3 \%$ \\
\hline $\begin{array}{l}\text { Planteó a los docentes el reto de aprendizaje institucional ante la implementación de } \\
\text { las TIC en el proceso de enseñanza y aprendizaje. }\end{array}$ & $55,4 \%$ \\
\hline $\begin{array}{l}\text { Planificó la implementación de las TIC en el proceso de enseñanza y aprendizaje, } \\
\text { considerando ciertos grados y asignaturas como base inicial para la ejecución del } \\
\text { proyecto en concordancia con su potestad. }\end{array}$ & $30,4 \%$ \\
\hline $\begin{array}{l}\text { Cumplió con estándares / pautas / normas existentes para la implementación de las } \\
\text { TIC en el proceso de enseñanza y aprendizaje. }\end{array}$ & $41 \%$ \\
\hline
\end{tabular}

Fuente: Elaboración propia de las investigadoras (2015).

De los resultados obtenidos se infiere la existencia de razones para que existan profesores que no posean las suficientes competencias técnicas en el uso educativo de las TIC, pues la gerencia educativa planificó el cambio de la visión institucional por la presencia de ellas en el proceso de enseñanza y aprendizaje, pero esta no se comunicó en amplio alcance, aunque si se planteó el reto del aprendizaje institucional en un porcentaje 
considerable; el profesorado no tiene un conocimiento acerca de lo planificado ni del cronograma de actividades establecido. Además llama la atención los porcentajes con respecto a la planificación de la implementación de las TIC en el proceso de enseñanza y aprendizaje, considerando ciertos grados y asignaturas como base inicial para la ejecución del proyecto, pues mientras el $44 \%$ expresa que fue realizada en concordancia con lineamientos establecidos, el 30,4\% dice que el gerente educativo lo realizó según su potestad; de este modo, se deja entrever la existencia de una brecha para algunas instituciones en cuanto al cumplimiento de lo planificado a nivel gubernamental.

Por una parte, al indagar si existió acondicionamiento de las aulas de clase para la implementación de las TIC en el proceso de enseñanza y aprendizaje, se obtuvo que el 85,1 \% del profesorado lo asintió; sin embargo, al preguntarse acerca de la distribución de los equipos y dispositivos en cuanto a las asignaturas y los correspondientes contenidos programáticos, se obtuvo que el $41,1 \%$ de los gerentes la realizaron como componente de la función de planificación, lo cual repercute en la respuesta sobre la poca disponibilidad de equipos en la institución, convirtiéndose este aspecto en una preocupación, pues los dispositivos son elementos del cambio, se presenta entonces una debilidad en el proceso de implementación de las TIC en el aula de clase que interfiere con el proceso de enseñanza y aprendizaje, ya que los profesores en un 58, $9 \%$, no disponen en el aula de los recursos tecnológicos. Si se quiere que las TIC sean un medio para enriquecer el aprendizaje y que los estudiantes aprendan a utilizarlas de manera eficiente, hay que dotar las instituciones de recursos tecnológicos, mejorar la conexión a internet y poseer competencias técnicas.

Por otra parte, al considerar el ámbito tecnológico en el que se desenvuelven los estudiantes, sus profesores han de tomar en cuenta aquellas características de las TIC que desde su punto de vista favorecen los procesos de enseñanza y aprendizaje, por ello se indagó acerca de esta aspecto, obteniéndose los resultados presentados en la Tabla 6. 
Tabla 6. Características de las TIC que desde el punto de vista de los profesores favorecen los procesos de enseñanza y aprendizaje

\begin{tabular}{|l|l|l|l|}
\hline Características de las TIC & Mucho & Poco & Nada \\
\hline Alta motivación & $83,9 \%$ & $13,1 \%$ & $3 \%$ \\
\hline Aprendizaje autónomo & $59,5 \%$ & $36,8 \%$ & $3,7 \%$ \\
\hline Aprendizaje cooperativo & $57,5 \%$ & $36,3 \%$ & $6,2 \%$ \\
\hline Facilidad de uso & $62,3 \%$ & $35,2 \%$ & $2,5 \%$ \\
\hline Almacenamiento, clasificación, publicación de contenidos & $57 \%$ & $32,7 \%$ & $10,3 \%$ \\
\hline Facilidad para actualizar información & $69,9 \%$ & $24,1 \%$ & $6 \%$ \\
\hline Individualización de la enseñanza & $45,7 \%$ & $49,4 \%$ & $4,9 \%$ \\
\hline Interactividad & $66,1 \%$ & $29,1 \%$ & $4,8 \%$ \\
\hline Variedad de códigos de información (texto, sonido e imágenes) & $63,3 \%$ & $27,7 \%$ & $9 \%$ \\
\hline
\end{tabular}

Fuente: Elaboración propia de las investigadoras (2015).

Según lo expresado por los profesores acerca de las características que favorecen altamente los procesos de enseñanza y aprendizaje, los porcentajes oscilan entre el 45,7\% y el $83,9 \%$ con respecto a las particularidades presentadas. Además, para poder conocer si los profesores consideran el contexto tecnológico en el cual se desenvuelven sus estudiantes, se investigó sobre los aspectos que los docentes suponen les apoyan las TIC en el proceso de enseñanza y aprendizaje. Los resultados obtenidos se muestran en la Tabla 7.

Tabla 7. Aspectos que los profesores consideran les apoyan las TIC en el proceso de enseñanza y aprendizaje

\begin{tabular}{|l|c|}
\hline \multicolumn{1}{|c|}{ Aspectos considerados } & Porcentaje \\
\hline Atención a la diversidad. & $50,6 \%$ \\
\hline Mejora de la atención en clase. & $74,4 \%$ \\
\hline Facilita la interdisciplinariedad. & $66 \%$ \\
\hline Obtención de materiales didácticos. & $54,8 \%$ \\
\hline Acompañamiento individualizado de los estudiantes. & $41 \%$ \\
\hline Co-evaluación entre pares. & $35,7 \%$ \\
\hline Mantenimiento de la disciplina en el aula. & $52,4 \%$ \\
\hline Comunicación con los padres. & $35,7 \%$ \\
\hline Motivación de los estudiantes. & $77,4 \%$ \\
\hline Refuerzo de contenidos básicos. & $60,7 \%$ \\
\hline Evaluación formativa. & $52,4 \%$ \\
\hline Facilita la comunicación escuela-familia. & $44 \%$ \\
\hline
\end{tabular}

Fuente: Elaboración propia de las investigadoras (2015).

Entre los aspectos que los profesores consideran les apoyan las TIC en el proceso de enseñanza y aprendizaje, se observa un porcentaje muy alto de $77,4 \%$ en la motivación a los estudiantes, lo cual mejora la atención en clase en un $74 \%$. Con un $66 \%$ facilita la 
interdisciplinariedad entre las diferentes disciplinas que se desarrollan en el nivel objeto de estudio, visualizado como positivo por los docentes por cuanto refuerza los contenidos de los programas de educación básica secundaria, aspecto que es valorado por los profesores en $60,7 \%$, también contribuye en un porcentaje importante en la evaluación formativa en un $52,4 \%$ y en algunas escuelas facilita la comunicación con la familia en un $44 \%$.

Indagando sobre el conocimiento que posee el profesorado sobre el contexto tecnológico en donde se desenvuelven los estudiantes, se consideró que al integrar las TIC en el campo educativo, se genera una gama de actitudes oscilantes entre la aceptación y el rechazo, así se obtuvo como resultado de las dificultades que se le presentan para la incorporación de las TIC en la práctica pedagógica lo que se muestra en la Tabla 8.

Tabla 8. Dificultades que se presentan para la incorporación de las TIC en la práctica pedagógica

\begin{tabular}{|l|c|}
\hline Dificultades & Porcentaje \\
\hline Falta de preparación. & $19,6 \%$ \\
\hline Escasa disponibilidad de equipos informáticos en el hogar. & $32,7 \%$ \\
\hline Poca adaptación de los materiales al currículo. & $21,43 \%$ \\
\hline Falta de adquisición de competencias en las TIC. & $22 \%$ \\
\hline Incremento del tiempo de dedicación a las actividades. & $21,4 \%$ \\
\hline Poca aceptación de la metodología por los estudiantes. & $6,6 \%$ \\
\hline Escasa disponibilidad de equipos informáticos en la institución. & $66 \%$ \\
\hline Problemas en la consecución de materiales didácticos. & $26,8 \%$ \\
\hline $\begin{array}{l}\text { Escasos conocimientos en el diseño de material instruccional apropiado al nivel } \\
\text { educativo }\end{array}$ & $13,7 \%$ \\
\hline
\end{tabular}

Fuente: Elaboración propia de las investigadoras (2015).

La falta de preparación, de adquisición de competencias en TIC, los problemas en la consecución de materiales didácticos y los escasos conocimientos en el diseño de material instruccional apropiado al nivel educativo reflejan que la formación y preparación para la implementación del uso educativo de las TIC no ha estado en un nivel adecuado. Además, la escasez de equipos tanto en la institución como en el hogar, poca adaptación de los materiales al currículo, el incremento del tiempo de dedicación a las actividades dejan entrever que existe una situación vinculada con la planificación y organización educativa.

Con respecto a la aceptación, se indagó acerca de la consideración que poseen los profesores en cuanto a la experiencia que vive al emplear las TIC, se obtuvo el resultado mostrado en la Tabla 9. 
Tabla 9. Consideración acerca del uso de las TIC

\begin{tabular}{|c|c|c|c|}
\hline $\begin{array}{l}\text { Consideración acerca del uso } \\
\text { educativo de las TIC. }\end{array}$ & Porcentaje & $\begin{array}{l}\text { Consideración acerca del uso } \\
\text { educativo de las TIC. }\end{array}$ & Porcentaje \\
\hline Agradable & $74,4 \%$ & Práctico & $66 \%$ \\
\hline Fácil & $29,8 \%$ & Importante & $66, \%$ \\
\hline Eficaz & $53,6 \%$ & Distractor & $5,9 \%$ \\
\hline Manejable & $60,7 \%$ & Innovador & $66, \%$ \\
\hline Rígido & $1,8 \%$ & Entretenido & $38,7 \%$ \\
\hline Complicado & $11,3 \%$ & Limitado & $8,9 \%$ \\
\hline Innecesario & $0,6 \%$ & Mediador & $25,6 \%$ \\
\hline Molesto & $1,2 \%$ & & \\
\hline
\end{tabular}

Fuente: Elaboración propia de las investigadoras (2015).

De acuerdo con los resultados, los profesores valoran el uso educativo de las TIC como una experiencia agradable en un $74,4 \%$, práctica, importante e innovadora en un 66 $\%$, aunque no la consideran fácil ante el $29,8 \%$ otorgado y la perciben complicada en un $11,3 \%$. Se manifiesta que se acepta, pero con alguna distancia.

Los profesores revelan actitudes positivas hacia las TIC, están conscientes de que son una realidad, reconocen sus potencialidades, sus bondades en el proceso de enseñanza y aprendizaje y han vinculado el cambio de la visión institucional planificada desde la gerencia educativa; sin embargo, no se detecta la conexión teoría - práctica. Esta actitud es un condicionante importante para la integración de las TIC en el proceso de enseñanza y aprendizaje, lo cual se considera por el 61, 9 \% de los profesores que opinó acerca de la acción gerencial ejercida hacia la planificación de la visión institucional como la obtención de un aprendizaje en los estudiantes que les permita prepararse para la sociedad del conocimiento, aspecto que se vincula con la posesión de competencias teleológicas en los gerentes educativos.

Adicionalmente, en las tablas 2, 3, 4, 6 y 7 surge la situación de la nula apropiación que posee el profesorado con respecto a las bases de datos, uso dado a las herramientas, deficiencias en las competencias técnicas, aún desconocimiento acerca de las características de las TIC que pueden favorecer los procesos de enseñanza y aprendizaje, así como de aspectos vinculados con estas para apoyar ese proceso, lo cual deja entrever la relación existente entre la gerencia educativa y la formación del profesor de su institución, pues la actualización del personal docente es prioritaria en este tipo de proyectos para facilitarles el trabajo, lo cual se vincula con la organización del recurso humano; por tal razón, 
al indagar acerca de las acciones que la gerencia de la institución efectuó en la organización del recurso humano para la implementación del uso educativo de las TIC, se obtuvo lo presentado en la Tabla 10.

Tabla 10. Las acciones que la gerencia de la institución efectuó en la organización del recurso humano para la implementación del uso educativo de las TIC

\begin{tabular}{|l|c|}
\hline \multicolumn{1}{|c|}{ Las acciones } & Porcentaje \\
\hline $\begin{array}{l}\text { Estableció los perfiles del personal docente necesario para la implementación de } \\
\text { las TIC en el proceso de enseñanza y aprendizaje. }\end{array}$ & $72,6 \%$ \\
\hline $\begin{array}{l}\text { Estableció los perfiles del personal administrativo necesario para la } \\
\text { implementación de las TIC en el proceso de enseñanza y aprendizaje. }\end{array}$ & $35,1 \%$ \\
\hline $\begin{array}{l}\text { Estableció los perfiles del personal técnico necesario para la implementación de } \\
\text { las TIC en el proceso de enseñanza y aprendizaje. }\end{array}$ & $25,6 \%$ \\
\hline $\begin{array}{l}\text { Organizó la formación del personal docente necesario para la implementación de } \\
\text { las TIC en el proceso de enseñanza y aprendizaje. }\end{array}$ & $47 \%$ \\
\hline $\begin{array}{l}\text { Organizó la formación del personal administrativo necesario para la la } \\
\text { implementación de las TIC en el proceso de enseñanza y aprendizaje. }\end{array}$ & $23,8 \%$ \\
\hline $\begin{array}{l}\text { Organizó la formación del personal técnico necesario para la implementación de } \\
\text { las TIC en el proceso de enseñanza y aprendizaje. }\end{array}$ & $17,2 \%$ \\
\hline
\end{tabular}

Fuente: Elaboración propia de las investigadoras (2015).

A través de las respuestas de los encuestados, se denota que en un porcentaje bajo, del $47 \%$, manifestaron que sí hubo organización para la formación del personal docente para la implementación de las TIC en el proceso de enseñanza y aprendizaje; de este modo, se evidencia una causa de lo encontrado en cuanto a la poca apropiación que posee el profesorado con respecto a las bases de datos, el desconocimiento sobre particularidades que las TIC poseen para favorecer los procesos de enseñanza y aprendizaje, uso dado a las herramientas y de estrategias que estas aportan para apoyar ese proceso, así como deficiencias en las competencias técnicas

Otro aspecto relacionado con la didáctica en el ámbito tecnológico en el que se desenvuelven los estudiantes corresponde a las actividades relacionadas con la utilización/creación de los contenidos y materiales de trabajo en el proceso de enseñanza mediante el uso de las TIC, en la investigación se encontró lo que se muestra en la Tabla 11. 
Tabla 11. Las actividades relacionadas con la utilización/creación de los contenidos y materiales de trabajo en el proceso de enseñanza mediante el uso de las TIC

\begin{tabular}{|l|c|c|c|}
\hline \multicolumn{1}{|c|}{ Actividades } & Siempre & A veces & Nunca \\
\hline $\begin{array}{l}\text { Incluye elementos que atraen la atención del estudiante para } \\
\text { mantener su interés en los aspectos más relevantes de las } \\
\text { actividades propuestas }\end{array}$ & $51,2 \%$ & $44,6 \%$ & $4,2 \%$ \\
\hline $\begin{array}{l}\text { El material es presentado de forma agradable, mantiene el } \\
\text { interés del estudiante y despierta la motivación del } \\
\text { aprendizaje. }\end{array}$ & $51,2 \%$ & $43,4 \%$ & $4,8 \%$ \\
\hline $\begin{array}{l}\text { Presenta los contenidos en forma progresiva según niveles de } \\
\text { complejidad tanto en el desarrollo del currículo como en los } \\
\text { ejercicios y problemas de aplicación. }\end{array}$ & $60,5 \%$ & $36,5 \%$ & $3 \%$ \\
\hline Diseña contenidos y objetos de aprendizaje reusables. & $50 \%$ & $45,1 \%$ & $4,9 \%$ \\
\hline Utiliza material apropiado para el nivel de estudio & $69,5 \%$ & $28,1 \%$ & $2,4 \%$ \\
\hline $\begin{array}{l}\text { Aborda temas novedosos y actualizados pertinentes al } \\
\text { currículo }\end{array}$ & $60,1 \%$ & $36,3 \%$ & $3,6 \%$ \\
\hline $\begin{array}{l}\text { Dispone de varias modalidades en la presentación de los } \\
\text { contenidos que permitan elegir la más favorable a las } \\
\text { condiciones y estilos de aprendizaje de los estudiantes }\end{array}$ & $39,9 \%$ & $55,4 \%$ & $4,7 \%$ \\
\hline
\end{tabular}

Fuente: Elaboración propia de las investigadoras (2015).

Se desprende de la Tabla 11 que existe un 44,6\% de los encuestados que a veces incluye elementos que atraen la atención del estudiante para mantener su interés en los aspectos más relevantes de las actividades propuestas, se plantea también que hay un 45,1 $\%$ que a veces diseña contenidos y objetos de aprendizaje reusables, además, existe un $55,4 \%$ que manifiesta que a veces dispone de varias modalidades en la presentación de los contenidos que permitan elegir la más favorable a las condiciones y estilos de aprendizaje de los estudiantes. Se refuerza de este modo que a pesar de que la gerencia ha planificado la visión institucional y potencializado el reto del aprendizaje organizacional, no se ha gestionado el conocimiento hacia nuevas maneras de actuar con el empleo de las TIC.

En cuanto a los cambios esperados en el contexto didáctico con el uso de las TIC, aparecen vinculados con un uso ocasional, se evidencia que los profesores en la reorganización del proceso de enseñanza no toman como punto de inicio el potencial didáctico de las TIC. Es así como al preguntar a los profesores acerca de las actividades que realizan en el proceso de enseñanza mediante el uso de las TIC, el porcentaje más alto de las respuestas se encuentra en la categoría de a veces para: planificar el uso de las TIC considerando los recursos disponibles en la institución, animar a investigar, ampliar y profundizar en determinados contenidos, orientar la realización de alguna actividad concreta de modo breve y efectivo, incorporar el uso de las TIC en el aprendizaje según las 
características de los estudiantes, propiciar la interacción de los estudiantes con las diferentes disciplinas, entre otras.

No obstante, en el proceso de enseñanza, el 58,3 \% de los profesores expresan manejar instrucciones claras sobre las actividades por realizar y sobre los resultados y logros que pretenden alcanzar, ofreciendo el 54,8 \% de los profesores realimentación y repaso del tema para aclarar dudas y reafirmar conocimientos. De allí que el 67,3\% dice que supervisa de modo continuo el trabajo de los estudiantes, el 53,6 \% respalda la colaboración en el aula o en el ambiente virtual, al establecer trabajos grupales a los estudiantes usando las TIC, reflejando de este modo ciertas competencias didácticas. Por otra parte, en el contexto didáctico sobre las estrategias de aprendizaje, nuevamente el porcentaje más alto de respuestas, que oscila entre el $47,6 \%$ y el $66,7 \%$ es en la categoría de a veces para las estrategias: desarrollo de pensamiento crítico en los estudiantes, integración del contexto mediante el trabajo en equipo, la realización de actividades de evaluación formativa, entre otras. Solo el $53,8 \%$ de los profesores siempre suministra apoyo adecuado para la resolución de problemas.

Ahora bien, al vincular el uso didáctico que los profesores de las instituciones objeto de estudio del Municipio San José de Cúcuta hacen de las TIC con las variables edad y años de servicio, se detectó que el 50,6 \% se encuentra entre 45 y 64 años de edad y el 45,8\% de los profesores posee más de 20 años de servicio; estos resultados evidencian que la praxis pedagógica está arraigada con la formación tradicional, se presenta de este modo una dificultad en cuanto al cambio de la metodología por utilizar, ya que se requiere por parte de los profesores un gran esfuerzo para la apropiación, aplicación e implicación de las TIC en su aula de clase y así posibilitar una enseñanza inclusiva que beneficie a los estudiantes y les oriente al aprendizaje significativo. Se deriva así, una deficiencia en la gerencia educativa que se vincula con sus competencias estratégicas al aún no haber establecido la brecha entre lo que es su institución hoy y aquella que será cuando se implemente plenamente las TIC en el proceso de enseñanza y aprendizaje, aplicando para ello acciones que conduzcan a la generación de compromiso, motivación y el reto del aprendizaje organizacional.

Además, se evidencia que aún no se contextualiza el proceso de enseñanza en la sociedad del conocimiento, elemento que debe configurar la visión institucional y que, por lo antes señalado de la diversidad existente en el pensamiento gerencial acerca de los fines institucionales, ha conducido a variaciones en el diseño de la visión, generando expectativas diferentes en los profesores; por ello, el porcentaje de $39,3 \%$ de profesores que siempre 
animan a la investigación, ampliación y profundización en determinados contenidos. El 48,8 $\%$ de profesores expresa que propician en el estudiante el descubrimiento al utilizar las TIC en el proceso de enseñanza, el 45,2 \%, señala que facilitan el aprendizaje significativo de los estudiantes a través de la resolución de problemas reales en el contexto social de los estudiantes, en un 41,7 \% facilitan la utilización de diversidad de medios considerando el alcance del estudiante a estos y además efectúan evaluaciones para determinar la existencia o no del aprendizaje significativo y solo un $29,8 \%$ se comunica con sus estudiantes con el empleo de las TIC que tiene a su alcance. Por consiguiente, se evidencia la existencia de ciertas competencias didácticas en los profesores.

En cuanto al proceso de evaluación, se buscó conocer las estrategias empleadas por los profesores para valorar a sus estudiantes mediante el uso de las TIC; tomando en cuenta que la evaluación es un tema que en educación requiere de una atención muy especial, más aun en los actuales paradigmas educativos en los que se ubica en el centro al estudiante y su aprendizaje. En este sentido, el compromiso es mayor si se emplean las TIC, el profesor requiere tener definido un plan de evaluación del aprendizaje y del desempeño que considere diversas dimensiones como son la: autoevaluación, coevaluación y heteroevaluación.

Se encontró que los profesores para valorar las condiciones iniciales de sus estudiantes utilizan entre un $50 \%$ y $64,3 \%$ herramientas como el glosario y los mapas mentales, en cuanto a contenidos: conceptuales, procedimentales y actitudinales, el profesor tiene la posibilidad de describir los rasgos más importantes del proceso de aprendizaje de los estudiantes; en contenidos actitudinales, el 6,37 \% usa las exposiciones, el 50 \%, trabajo colaborativo. Para valorar contenidos conceptuales, el 73,2 \% utiliza el trabajo colaborativo, mientras que se usan muy poco o nada los puzzles y las redes sociales. Por lo que se considera necesario recabar información de manera permanente y a través de distintos medios y herramientas, para emitir juicios y realizar a tiempo las acciones pertinentes que ayuden a mejorar el rendimiento y desempeño de los estudiantes.

Por una parte, según la valoración de contenidos procedimentales, las herramientas más utilizadas son las prácticas y las narraciones en un 57,7 \% y 51,8\%, respectivamente, y la menos empleada, la elaboración de videos en un $17,3 \%$. En lo que respecta a la autoevaluación de los estudiantes, los instrumentos más utilizados son la guía de observación y el auto-informe, ambos en un 44,1 \%, y las rúbricas las menos empleadas en un 19 \%. En lo referente a la co-evaluación entre pares de estudiantes, el instrumento más 
empleado es la guía de observación en un 53,6 \%, y la menos utilizada fue la lista de cotejo en un $14,9 \%$. En términos generales, el $52,4 \%$ de los profesores han considerado que las TIC les favorecen para realizar evaluación formativa, mientras que un $22,1 \%$ de los profesores expresa carencia de competencias en TIC para aplicarlas. En relación con los datos aportados por los profesores, se detectó apropiación tanto en las técnicas como en los instrumentos utilizados para valorar el conocimiento y el desempeño de los estudiantes, pues ambos se usan con mucha frecuencia también en la educación presencial tradicional.

Por otra parte, el 57,7 \% de los profesores expresó que usa las TIC para: programar, administrar y controlar el tiempo dedicado a la labor docente; el 51,8 \%, implementa, estrategias de comunicación y seguimiento del aprendizaje de los estudiantes; el 33,3\%, mejorar y renovar la gestión institucional, en la relación con la comunidad y especialmente en escuela-familia; y un $23,2 \%$ usa los espacios virtuales existentes en la institución para facilitar y promover la interacción con los padres y representantes, se evidencia la presencia de ciertas competencias desde el punto de vista de la gestión en los profesores del contexto objeto de estudio.

Para promover el desarrollo de habilidades sociales de sus estudiantes se evidenció que el $79,2 \%$ de los profesores integra las TIC con nuevas formas de socialización y el desarrollo de ciudadanía digital; el 52,4 \% agrega las TIC conforme a prácticas que favorezcan el respeto a la diversidad, igualdad de trato, condiciones saludables en el acceso y uso; el 45,8 \% incluye procedimientos de prevención, cuidado de la salud de los estudiantes y del ambiente educativo; el 42,3 \% promueve el desarrollo de habilidades sociales para la participación y el aprendizaje colaborativo y en red; el 44,6 \% incorpora las TIC conforme a prácticas que favorezcan el cumplimiento de las normas éticas y legales; y el 39,9 \% modela y aplica en las experiencias de aprendizaje en que se utilicen TIC, prácticas de reflexión y de toma de decisiones respecto a dilemas éticos y legales relacionados con su uso. Por lo tanto, se considera la presencia de competencias desde el punto de vista social, ético y legal que los profesores aplican en el proceso de enseñanza y aprendizaje mediante el uso de las TIC.

De igual forma, el gerente educativo debe poseer competencias y capacidades para gerenciar el cambio (Aguilar, Pereyra, y Miguel, s.f.; Sulbarán, 1998; López, 2002, Aguaded y Tirado, 2008; Azuaje, 2005; Páez, s.f.). Al investigar sobre ello, se encontró que los gerentes poseen conocimientos estratégicos con respecto a la formación y desarrollo del capital humano, aunque no de modo suficiente ante el $47 \%$ resultante de la indagación realizada en 
la formación del personal docente necesario para la implementación de las TIC en el proceso de enseñanza y aprendizaje; además con las respuestas ofrecidas por los gerentes informantes en las entrevistas se tiene: informante 8 manifiesta que la formación y el desarrollo del capital humano para la implementación de las TIC en las instituciones educativas no se ha tomado con la seriedad que se requiere. De vez en cuando se hacen convocatorias generales que no permiten la verdadera capacitación a través de talleres o encuentros con especialistas en el tema; el informante 4 afirma que tienen una barrera de aceptación al cambio, al gobierno le hace falta incentivar más a los docentes; el informante 10 asegura que es necesario capacitar a los profesores realmente, no charlas, que el Ministerio de Educación haga acompañamiento y verdadera capacitación a los profesores y no se cree resistencia; el informante 12 menciona que para el manejo de las TIC los docentes deben estar convencidos de que son muy importantes. Estas respuestas aportan el significado de la apropiación que de las TIC han de realizar los profesores.

Asimismo: se consideró que el 72,6 \% de los encuestados contestó que el gerente estableció los perfiles del personal requerido para la implementación del uso educativo de las TIC; aunque un $22 \%$ plantease falta de adquisición de competencias en TIC, así como que el $15,5 \%$ de profesores expresó que la gerencia ha efectuado seguimiento a los resultados obtenidos de la implementación de las TIC.

Según las respuestas ofrecidas por los gerentes en las entrevistas, se evidenció que poseen competencias relacionadas con el conocimiento acerca de los fines institucionales necesarios para el diseño de la visión, entre ellas: informante 5 afirma que permite al estudiante el acceso a la tecnología para que lo emplee en su vida diaria; informante 9, dice que fortalece el proceso de enseñanza aprendizaje con las TIC; informante 13 asegura que lo que se espera es que la calidad de la educación mejore; informante 11 menciona que forman estudiantes competentes, pues lo que se busca es que el muchacho pueda mostrar sus competencias no solo en el país, sino en todas partes. Respuestas que denotan una diversidad de fines institucionales en el pensamiento gerencial, lo cual tergiversa el diseño de la visión institucional, generándose de este modo diferencias en la planificación estratégica de las instituciones y por ende diversas visualizaciones y posturas del profesorado acerca de su actividad pedagógica.

Igualmente, se evidencian debilidades con respecto a las competencias legales que deben poseer los gerentes educativos, pues al haber respondido en la entrevista: informante 14 afirma que siendo un lineamiento del Ministerio de Educación, la institución educativa está 
obligada legal y jurídicamente a adaptar los programas, institución, plan curricular y sobre todo hacer cumplir a los docentes; informante 2 afirma la parte legal y jurídica no la conoce e infiere que el análisis de leyes y normativas es muy escaso. Se manifiestan conocimientos sobre prioridades gubernamentales, aunque no se establecen vinculaciones de las acciones que se efectúan en la institución como contribución de esta con las preferenciales del Plan Nacional de Desarrollo (Ley 1753) (República de Colombia, 2015). La educación en Colombia posee un fundamento reglamentario en el Artículo 67 de la Constitución Política de Colombia (1991), planteando una función social que busca el acceso al conocimiento, a la ciencia, a la técnica y a bienes y valores de la cultura; en la institución escolar al implantar las TIC con uso educativo, lo estipulado en la Constitución no pierde vigencia y por tanto la gerencia ha de continuar realizando la vinculación con lo establecido.

En razón a los resultados obtenidos, se deduce que los profesores utilizan las TIC y emplean estrategias para abordar los contenidos, pero aún no se gestiona el conocimiento en la escuela dentro del entorno de la innovación educativa, por cuanto se continúan utilizando estrategias de la praxis tradicional en el ámbito de las TIC, siendo dependiente esta situación de las debilidades existentes en las competencias teleológicas de los gerentes educativos.

\section{Conclusiones}

En las instituciones educativas de educación básica secundaria del Municipio de San José de Cúcuta beneficiadas con el programa Computadores para Educar, los gerentes han delineado visiones institucionales diversas, lo cual representa un impedimento para que se realice el proceso de enseñanza y aprendizaje en concordancia con los reales fines que se persiguen con la implementación de las TIC para su uso educativo. Se revela así la importancia de la relación gerencia educativa y didáctica en cuanto al uso de las TIC, pues los profesores han de realizar las actividades en el proceso educativo considerando los objetivos institucionales que deben estar orientados hacia el aprendizaje de los estudiantes en búsqueda de su preparación para su inserción en la sociedad del conocimiento. El rol de la didáctica ante la presencia de las TIC en el contexto educativo de las instituciones municipales de educación básica secundaria de la ciudad de Cúcuta no ha logrado la optimización del aprendizaje, la integración de la cultura y el desarrollo personal, pues las debilidades encontradas en cuanto a las competencias técnicas y didácticas así lo evidencian. 
Desde la perspectiva del gerente, la labor de guía que toma en cuenta elementos provenientes del entorno y del seno organizacional como información útil para la toma de decisiones adaptativas acordes con el cumplimiento de las metas propuestas, conduciendo a la realización de actividades por el profesorado, no está ocurriendo en la forma que plantea el deber ser. Se aprecia debilidad en cuanto a competencias teleológicas en los gerentes educativos, lo que conduce a deficiencias en el diseño de la visión institucional y por ende al establecimiento de la misión y del plan estratégico acorde, lo cual involucra que en el aspecto didáctico, relacionado con los planes operativos de la institución, se presenten vacíos que impiden un aprendizaje favorecedor en los estudiantes para el mundo globalizado en donde han de insertarse. De allí que la relación que emerge entre la didáctica, gerencia y uso educativo de las TIC es la necesidad de conocimiento acerca de la integración que debe existir entre los miembros de la institución para que se produzca el cambio, fundamentado en la nueva visión, valores, costumbres y maneras de hacer las cosas.

Se aprecia que desde la gerencia no se ha diseñado de modo congruente el modelo ideal de lo que debería ser y así trazar la brecha existente entre lo real y lo ideal para que la institución evolucione a su transformación. Aún la gerencia educativa no ha identificado las condiciones que deben ser rechazadas y reemplazadas para así proyectar etapas de desarrollo y programar su realización. Ya que se espera que la gerencia educativa ha de liderar el cambio ofreciendo a los profesores, mediante la formación pertinente, el conocimiento acerca de las oportunidades que les brindan las diversas herramientas en las TIC de las que dispone en la institución, induciéndoles a su uso educativo y conduciendo a la transformación de la cultura existente en su praxis pedagógica, efectuando una renovación en sus roles para que sean facilitadores del conocimiento.

El deber ser de la relación entre la gerencia y la didáctica ante el uso educativo de las TIC involucra: el aprendizaje efectivo de los estudiantes, la formación y presencia de competencias acordes en el profesorado y en el gerente educativo para gestionar el cambio con la instauración de una nueva cultura escolar, pues se han de adaptar a la situación de la institución considerando los fines perseguidos, los lineamientos establecidos y el pensamiento estratégico que permita abordar el cambio en los procesos de enseñanza y aprendizaje y evaluación acorde a las circunstancias que conducen al mismo.

En el contexto de estudio se presenta de manera incipiente una relación entre didáctica, gerencia educativa y el uso educativo de las TIC. Se dice incipiente porque los resultados plasman entre los elementos intervinientes la necesidad de formación del recurso 
humano es decir, profesorado y gerentes educativos, se denota la no existencia de objetivos globales e interdisciplinares que conduzcan a concretar la transformación institucional de manera que se trace una novedosa cultura escolar que considere el currículo, la pedagogía, el aprendizaje y la evaluación, lo cual se causa por las debilidades existentes en la formación y o actualización de los profesores y de los gerentes educativos para el cumplimiento de sus funciones. De allí que las entidades gubernamentales que auspician el Programa Computadores para Educar están perdiendo esfuerzos económicos, han dispuesto la tecnología, pero han sido débiles en cuanto a la propuesta de formación del capital humano involucrado. Para lograr formar al ser humano integral con el uso educativo de las TIC debe estar presente una estrategia sistémica que aborde todos los aspectos de la cultura escolar.

\section{Referencias}

Aguaded, José y Tirado, Ramón. (2008). Los centros TIC y sus repercusiones didácticas en primaria y secundaria en Andalucía. Revista Educar, (41), 61-90. Recuperado de http://ddd.uab.cat/pub/educar/0211819Xn41/0211819Xn41p61.pdf

Aguilar, Margarita, Pereyra, Luis y Miguel, Ricardo. (s.f.). Clima, Cultura y Cambio Organizacional. Caracas: Universidad Nacional Abierta. Recuperado de http://cursoampliacion.una.edu.ve/desarrollorganizacional/paginas/lectura9climacultura. $\underline{\mathrm{pdf}}$

Area, Manuel. (2005). Tecnologías de la información y la comunicación en el sistema escolar. Una revisión de las líneas de investigación. Revista Electrónica de Investigación y Evaluación Educativa 11(1), 3-25. Recuperado de http://www.uv.es/relieve/v11n1/RELIEVEv11n1 1.pdf

Armijo, Marianela. (2009). Manual de planificación estratégica e indicadores de desempeño en el sector público (Versión preliminar). ILPES/CEPAL. Recuperado de http://www.cepal.org/ilpes/noticias/paginas/3/38453/manual planificacion estrategica.p $\underline{\mathrm{df}}$

Arnoletto, Eduardo. (2004). Fundamentos de la Administración de las organizaciones. Recuperado de http://www.eumed.net/libros-gratis/2014/1395/index.htm

Azuaje, Eduardo. (2005). Pensamiento gerencial. Su desarrollo. Caracas: Ediciones Urania.

Cabero Almenara, Julio. (2007). Tecnología educativa. Madrid: Mc GrawHill.

Cabero Almenara, Julio. (2000). Nuevas tecnologías aplicadas a la educación. Madrid: Síntesis.

Carneiro, Roberto. (2002). A evolução del e-learning em Portugal: contexto e perspectivas. Lisboa: Instituto para a Inovação na formação. 
Cerdá, Carlos. (2004). Jurguen Habermas: La sociología intersubjetiva de la comunicación en el mundo de la vida. En Marta Fernández (Comp.), Nombres del pensamiento social. Miradas contemporáneas sobre el mundo que viene (pp.151-168). Buenos Aires: Del Signo.

Chiavenato, Idalberto. (2001). Administración de recursos humanos. México: McGraw-Hill.

Coll, Cesar y Martí, Eduardo. (2001). La educación escolar ante las nuevas tecnologías de la información y la comunicación. En Cesar Coll, Jesús Palacios y Álvaro Marchesi (Comps.), Desarrollo psicológico y educación (Vol. 2. Psicología de la educación escolar; pp. 623-655). Madrid: Alianza.

Coll, Cesar, Mauri, María y Onrubia, Javier. (2008). Análisis de los usos reales de las TIC en contextos educativos formales: una aproximación sociocultural. Revista Electrónica de Investigación Educativa, 10(1), 1-18. Recuperado de http://redie.uabc.mx/vol10no1/contenido-coll2.html

Coll, Cesar, Onrubia, Javier y Mauri, María. (2007). Tecnología y prácticas pedagógicas: las TIC como instrumentos de mediación de la actividad conjunta de profesores y estudiantes. Anuario de Psicología, 38(3), 377-400. Recuperado de http://revistes.ub.edu/index.php/Anuario-psicologia/article/viewFile/8407/10382

Coll, Cesar. (2004). Psicología de la educación y prácticas educativas mediadas por las tecnologías de la información y la comunicación. Una mirada constructivista. Sinéctica (25), 1-24. Recuperado de http://www.redalyc.org/articulo.oa?id=99815899016

Comisión Económica para América Latina y el Caribe. (2010). Monitoreo del plan eLAC 2010 (Capítulo Educación). Recuperado de http://www.cepal.org/socinfo/noticias/documentosdetrabajo/5/40915/parteb.pdf

Comisión Económica para América Latina y El Caribe. (2008). Reduciendo la brecha digital: avances hacia las metas en educación del eLAC2010. NEWSLETTER, (6), 2-3. Recuperado de http://www.cepal.org/socinfo/noticias/noticias/7/34247/NEWS6esp.pdf

Cuban, Larry. (2001). Oversold \& Underused. Computers in the Classroom. Cambridge, MA: Harvard University Press.

Drucker, Peter. (2002). Los Desafíos de la gerencia para el siglo XXI. Barcelona: Editorial Norma.

Hernández, Pedro. (2005). If not here, where? Understanding teachers use of 21 technology in Silicon Valley schools. Journal of Research on Technology in Education, 38(1), 3964.

Hernández, Roberto, Fernández, Carlos y Baptista, Pilar. (2006). Metodología de la Investigación (4ª . ed.). México: McGraw Hill.

International Society for Technology in Education. (2007). National Educational Technology Standards for Students (NETS) (2nd. ed.). Washington: ISTE. 
IT Governance Institute. (2007). Control Objectives for Information and related Technology (COBIT) 4.1. Recuperado de http://www.isaca.org/knowledgecenter/cobit/pages/downloads.aspx

Joyanes, Luis. (1997). Cibersociedad. Los retos sociales del siglo XXI. Madrid: McGraw Hill.

López, Carlos. (2002). Gerencia basada en valor GBV. Recuperado de http://www.gestiopolis.com/gerencia-basada-valor-gbv-value-based-management-vbm/

Mallart, Juan. (2001). Didáctica: concepto, objeto y finalidad. En Felix Sepúlveda y Nuria Rajadell (Coords.), Didáctica General para Psicopedagogos (pp. 23-57). Madrid: UNED.

Ministerio de Tecnología de la Información y las Telecomunicaciones y Ministerio de Educación de Colombia. (s.f.). Evaluación de impacto y de la sostenibilidad de computadores para educar en la calidad de la educación en las sedes educativas beneficiadas. (René Lemoine, Director del Proyecto). Recuperado de http://www.computadoresparaeducar.gov.co/paginaweb/images/biblioteca/Estudio\%20d e\%20impacto/Articulo\%20impacto\%20Computadores\%20para\%20Educar\%20Colombi a.pdf

Onrubia, Javier. (2005). Aprender y enseñar en entornos virtuales: actividad conjunta, ayuda pedagógica y construcción del conocimiento. Revista de Educación a Distancia, 4(2), 116. Recuperado de http://www.um.es/ead/red/M2/

Organización para la Cooperación y el Desarrollo Económicos. (2007). Manual de Oslo. Directrices para la recogida e interpretación de información relativa a innovación (Trad. María Paloma Sánchez y Rocío Castrillo). Recuperado de http://www.madrid.org/bvirtual/BVCM001708.pdf

Páez, Pablo. (s.f.). La innovación en la práctica educativa de equipos gerenciales. Recuperado de http://elmayorportaldegerencia.com/Publicaciones/\%5BPD\%5D\%20Publicaciones\%20\%20La\%20Innovacion\%20Educativa.pdf

Pineda, Migdalia. (2009). Desafíos actuales de la sociedad del conocimiento para la inclusión digital en América Latina. Disertaciones, 2(1), 10-25. Recuperado de http://erevistas.saber.ula.ve/index.php/Disertaciones/article/view/48/41

República de Colombia. (2015). Ley 1753 Plan Nacional de Desarrollo 2014-2018 "todos por un nuevo país". Recuperado de http://www.secretariasenado.gov.co/senado/basedoc/ley 1753 2015.html

República de Colombia. Asamblea Nacional Constituyente (1991). Constitución Política de

Recuperado

de http://www.senado.gov.co/images/stories/Informacion General/constitucion politica.pdf

Rodríguez, Rosa. (2004). Transmodernidad. Barcelona: Anthropos. 
Sulbarán, Juan. (1998). El rol de la gerencia en el proceso de cambio. Economía, (14), 193206. http://iies.faces.ula.ve/Revista/Articulos/Revista 14/rev14sulbaran.htm

Tripier, Benjamin. (18 de agosto, 2002). Resistencia al cambio un peligro manejable. El Nacional, p. E5.

Van Den Berghe, Edgar. (2005). Gestión y Gerencia Empresarial aplicada al siglo XXI. Bogotá: Ecoe Ediciones. 